\title{
A Case Report of Pneumocystis Jiroveci Pneumonia in a Patient with Metastatic Breast Cancer
}

\author{
ABHIJIT RAY ${ }^{1}$, BRIAN KHONG ${ }^{2}$ and HUNG T. KHONG ${ }^{1}$ \\ ${ }^{1}$ Huntsman Cancer Institute, University of Utah, Salt Lake City, UT, U.S.A.; \\ ${ }^{2}$ Touro University California, Vallejo, CA, U.S.A.
}

\begin{abstract}
We describe a 69-year-old woman with metastatic breast cancer who developed dyspnea on exertion, persistent cough, fever and fatigue while on everolimus and exemestane combination. The initial differentials included opportunistic infection such as pneumocystis jiroveci pneumonia (PJP) vs. pneumonitis. Bronchoalveolar lavage (BAL) from bronchoscopy revealed PJP. The patient recovered after appropriate treatment. We also correlated the progressive decrease in her absolute lymphocyte count with $P J P$ infection and recovery. This is the second case that PJP has been described in patients with breast cancer receiving everolimus. Clinicians should be vigilant in their monitoring of patients on everolimus-based regimens and promptly institute appropriate therapy to reduce and prevent morbidity and mortality.
\end{abstract}

Pneumocystis jiroveci pneumonia (PJP) is an opportunistic and potentially fatal fungal infection in immunosuppressed patients (1). It is more common in patients with acute immune suppression associated with HIV infection (1), transplant patients receiving immune-suppressant drugs (2) or patients with hematological malignancies (3). Another patient population predisposed towards PJP are those receiving prolonged course of corticosteroids (4). Patients receiving dose-dense chemotherapy in solid malignancies resulting in acute depression of lymphocyte count show an increased rate of reported PJP cases (5) even though it is often difficult to distinguish PJP from other forms of pneumonia or pneumonitis (6).

The combination of everolimus and examestane was approved for the treatment of metastatic breast cancer in 2012 . Everolimus prevents the phosphorylation of the mammalian

Correspondence to: Dr. Hung T. Khong, University of Utah Huntsman Cancer Institute, 2000 Circle of Hope, Salt Lake City, UT 84112, U.S.A. Tel: +1 8012134260, e-mail: hung.khong@hci.utah.edu

Key Words: Pneumocystis jiroveci pneumonia, metastatic breast cancer, everolimus, immunosuppression, chemotherapy. target of repamycin complex 1 (mTORC1) thereby inhibiting phosphatidylinositide 3-kinase ( $\mathrm{PI} 3 \mathrm{~K}) /$ protein kinase $\mathrm{B}$ (AKT)/mammalian target of rapamycin (mTOR) signaling pathway and proliferation there by preventing the escape of aromatase inhibitor (AI)-resistant breast cancer cells (7). It is also widely used as an immunosuppressive agent in the transplant setting. Everolimus binds to mTOR which inhibits signal transduction via interleukin-2 (IL-2) and block T- and B-cell activation by cytokines (8). Everolimus-induced PJP has earlier been reported in patients with renal transplant (9), renal cell carcinoma (10) and metastatic pancreatic neuroendocrine tumors (11).

There is one prior report in the literature of a patient with metastatic breast cancer who developed PJP following treatment with everolimus (6). We report a case where a patient developed PJP while on everolimus in combination with examestane for metastatic breast cancer.

\section{Case}

A 69-year-old woman with metastatic estrogen receptor/progesterone receptor (ER/PR)-positive, human epidermal growth factor receptor (HER)-2-negative breast cancer, who had been on treatment with everolimus and examestane for five months. The patient was presented to our breast oncology clinic in July 2014 for persistent dry cough, fever, and progressive fatigue and dyspnea on exertion for two weeks. She was initially diagnosed with metastatic lobular breast cancer with diffuse bony metastases in April 2013 and was started on letrozole $2.5 \mathrm{mg}$ daily. Her disease progressed with four brain metastases detected, for which she underwent stereotactic radiosurgery. Letrozole was discontinued and the combination of $10 \mathrm{mg}$ everolimus daily and $25 \mathrm{mg}$ examestane daily was started. After two and a half months, everolimus dose was reduced to $7.5 \mathrm{mg}$ due to progressive neutropenia.

After evaluating the patient in the clinic, we were concerned about opportunistic infection such as PJP since her absolute lymphocyte count (ALC) had been progressively decreasing from a baseline of $0.7 \mathrm{k} / \mu \mathrm{l}$ to $0.2 \mathrm{k} / \mu \mathrm{l}$. Everolimus- 
related pneumonitis was also in the differentials. A chest Xray was obtained that showed possible new mild patchy opacities (Figure 1A). CT chest showed progressive multifocal interstitial and airspace disease (Figure 1B). At presentation to clinic, she had a white blood cell count of $1.98 \mathrm{k} / \mu \mathrm{l}$, hemoglobin/hematocrit of $10.7 / 30.8$, platelet of $224 \mathrm{k} / \mu \mathrm{l}$ absolute neutrophil count of $1.5 \mathrm{k} / \mu \mathrm{l}$, and ALC of $0.2 \mathrm{k} / \mu \mathrm{l}$. The patient was admitted for further workup and management.

Patient was started on empiric antibiotics of zosyn and PJP-dosing bactrim DS. Azithromycin for atypical coverage was added 2 days later due to continued fever. Blood and urine were collected for culture and sensitivity and no growth was seen. Calcofluor White Stain for fungal elements was negative. Blood and urine culture were negative. $(1,3)$ beta-D-glucan was negative for fungal infection. The cultures for Herpes Simplex Virus and nocardia were negative. Further tests were negative for acid fast bacteria for the detection of mycobacterium tuberculosis. Broncho alveolar lavage (BAL) was negative to malignant cells. BAL was negative for viral panel as well as for aspergillus galactomannan. BAL fluid via real time PCR tested positive for PJP but negative for bordetella pertussis, mycoplasma pneumonia, chlamydia pneumonia, cytomegalovirus, legionella pneumophila.

The fever finally normalized to $98.8^{\circ} \mathrm{F}$ after 5 days of treatment with bactrim. Patient was discharged for home treatment after 6 days of hospitalization on bactrim for PJP and a 21 day prednisone taper for inflammation. Exemestane was continued without everolimus. She also required home $\mathrm{O}_{2}$ at the time of discharge. Six days post discharge her energy levels had improved and she was able to walk up and down the stairs without significant problems. She had no fever, chills, nausea, vomiting, chest pain, abdominal pain nor shortness of breath. She had good appetite and had been eating well. The rest of 10 system review was negative. Sixty seven days post discharge her ALC normalized to $1.1 \mathrm{k} / \mu \mathrm{l}$.

In order to understand the relationship between everolimus-induced lymphopenia and the onset of her symptoms and diagnosis of PJP, we followed the ALC from baseline prior to starting everolimus, through her diagnosis of PJP and subsequent treatment until resolution of her symptoms. The result demonstrated a gradual decrease in ALC during everolimus therapy, from $0.7 \mathrm{k} / \mu \mathrm{l}$ at baseline to $0.2 \mathrm{k} / \mu \mathrm{l}$ prior to and during diagnosis and treatment for PJP. The ALC recovered to baseline upon resolution of her symptoms (Figure 2).

\section{Discussion}

Approximately $30 \%$ of ER-positive breast cancer patients on estrogen deprivation using aromatase inhibitors (AIs) develop resistance following long-term treatment (12). Activation of the PI3K/AKT/mTOR pathway is considered clinically relevant for tumor escape in estrogen-deprived conditions (13). PI3K/AKT/mTOR pathway inhibitors such as rapamycin and its derivative everolimus have been under study as potent activators of AI drugs as well as immunosuppressive drugs that both maintain similar rates of efficacy and could optimize the renal function and diminish the side effects (14). $\mathrm{PI} 3 \mathrm{~K} / \mathrm{AKT} / \mathrm{mTOR}$ signaling pathway is involved in several fundamental cellular functions such as cell growth, proliferation and survival (14). mTOR function is central in a signaling cascade that directs the integration of diverse environmental inputs in the immune microenvironment by regulating the function of several immune cell types, including dendritic cells, B-cells or regulatory/effector T-cells and prevent maturation of the dendritic cells into antigen presenting cells (APCs) that stimulate T-cells $(14,15)$. Inhibition of the mTOR pathway affects the function of both $\mathrm{CD} 4^{+}$helper T-cells and $\mathrm{CD} 8^{+}$effector T-cells. In the absence of mTOR signaling, $\mathrm{CD} 4^{+}{ }^{+}$-cells cannot differentiate into effector subsets (16) while $\mathrm{CD}^{+}{ }^{+} \mathrm{T}$-cells differentiation and trafficking are also impaired by mTOR inhibition $(17,18)$. In addition, inhibition of mTOR pathway promotes the production of immunosuppressive regulatory T-cells (16). Such immunosuppressive activity is beneficial for solid-organ transplant patients. However, this may result in immune suppression in cancer or transplant patients leading to infection with opportunistic pathogens such as $P$. jiroveci.

Previous studies have noted that PJP among immunosuppressed non-HIV infected patients can be more severe and have a sudden onset $(19,20)$, resulting in a high mortality rate of $50 \%$ in non-HIV infected patients with PJP $(19,21,22)$. A delay in treatment is possibly related to the delay in the diagnosis of PJP, for which the clinical manifestations and radiologic abnormalities are nonspecific, thereby making it difficult to differentiate PJP from other opportunistic pulmonary infections (23). Most importantly, the diagnostic yield of staining methods for respiratory samples for $P$. jiroveci is limited (24). All patients manifest a ground glass opacity in their chest X-ray and CT of the chest, but this is indistinguishable from other forms of pneumonia. One method of detection of PJP is evaluating the levels of $(1,3)-\beta$ D-glucan. In a retrospective study the performance characteristics of $(1,3)-\beta$-D-glucan detection in sera from HIVinfected patients and patients with a hematological malignancy were excellent for the diagnosis of PJP, with a sensitivity of $100 \%$ and a specificity of $96.4 \%$ at a cutoff value of $100 \mathrm{pg} / \mathrm{ml}$ (3). However a recent case study reported an HIV positive patient with PJP without elevated $(1,3)-\beta$-D-glucan (25). $(1,3)-\beta$-D-glucan levels in our patient were negative.

Since culturing $P$. jirovecii in vitro with conventional staining methods show low sensitivity (38\%-53\% in sputum), the use of PCR technique using BAL for the diagnosis of PJP in patients is perhaps the most reliable method of identification $(26,27)$. A meta-analysis of 17 trials for a sensitivity and 

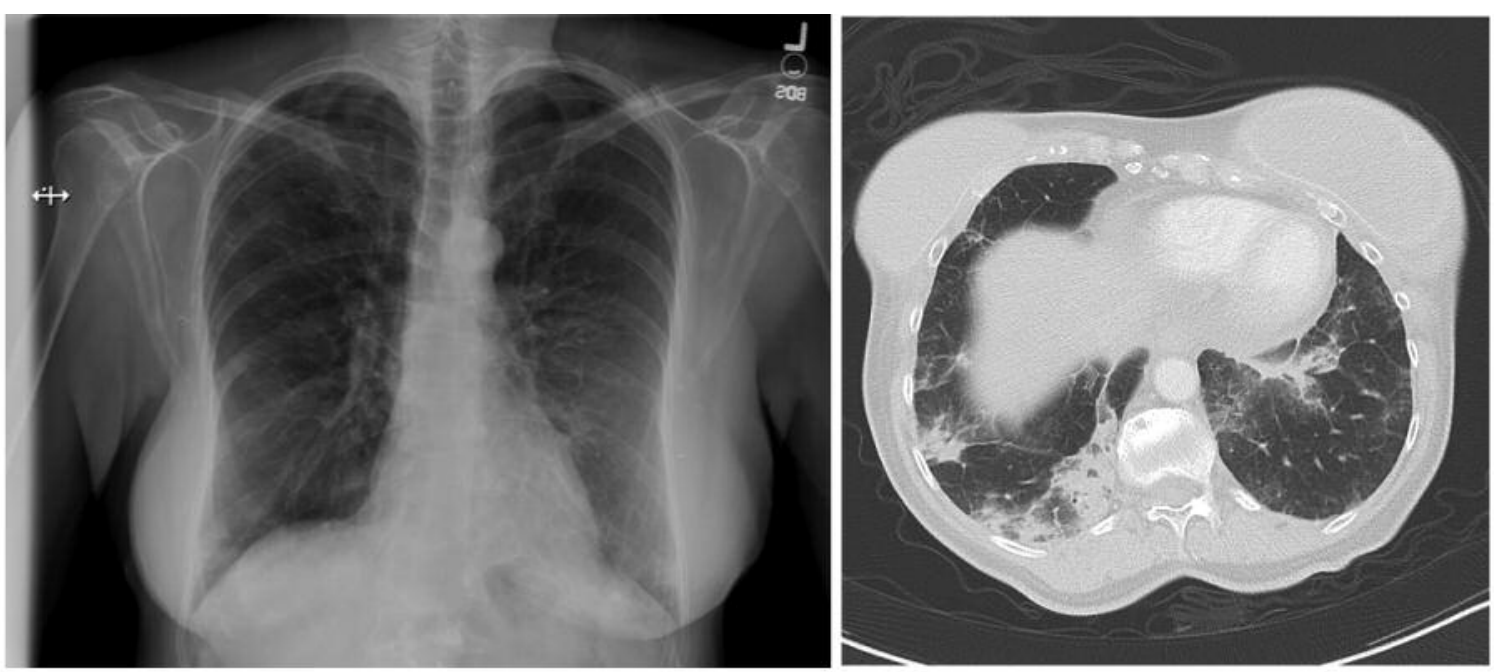

Figure 1. (A) X ray of patient with pneumocystis Jiroveci Pneumonia showing mild patchy opacities (B) CT of chest showed progressive multifocal interstitial and airspace disease.

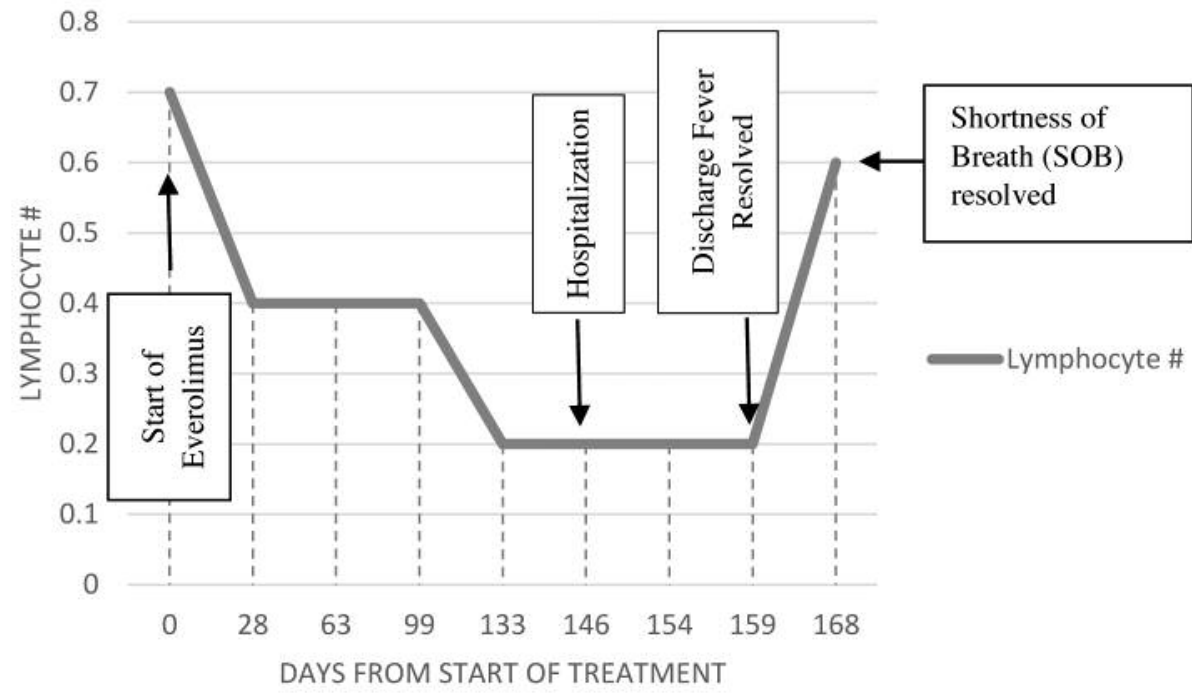

Figure 2. The graph shows the change of ALC of the patient from the beginning of everolimus therapy to the patient's release from hospitalization for PJP.

specificity values using BAL to detect PJP via PCR with a 95\% confidence interval was $98.3 \%$ and $91.0 \%$ respectively (26). Our patient was positive to PJP using real time PCR.

Everolimus in combination with examestane has been used more frequently in the management of metastatic breast cancer. Treating clinicians should be vigilant in their monitoring of patients on everolimus-based regimens since early recognition of symptoms secondary to opportunistic infection in these immunocompromised patients, such as PJP may lead to improved clinical outcome.

\section{Acknowledgements}

None.

\section{References}

1 Radhi S, Alexander T, Ukwu M, Saleh S and Morris A: Outcome of HIV-associated Pneumocystis pneumonia in hospitalized patients from 2000 through 2003. BMC Infect Dis 8: 118, 2008.

2 Iriart X, Challan Belval T, Fillaux J, Esposito L, Lavergne RA, Cardeau-Desangles I, Roques O, Del Bello A, Cointault O, 
Lavayssiere L, Chauvin P, Menard S, Magnaval JF, Cassaing S, Rostaing L, Kamar N and Berry A: Risk factors of Pneumocystis pneumonia in solid organ recipients in the era of the common use of posttransplantation prophylaxis. Am J Transplant 15: 190199, 2015.

3 Desmet S, Van Wijngaerden E, Maertens J, Verhaegen J, Verbeken E, De Munter P, Meersseman W, Van Meensel B, Van Eldere J and Lagrou K: Serum (1-3)-beta-D-glucan as a tool for diagnosis of Pneumocystis jirovecii pneumonia in patients with human immunodeficiency virus infection or hematological malignancy. J Clin Microbiol 47: 3871-3874, 2009.

4 Liebling M, Rubio E and Ie S: Prophylaxis for Pneumocystis jiroveci pneumonia: is it a necessity in pulmonary patients on high-dose, chronic corticosteroid therapy without AIDS? Expert Rev Respir Med 9: 171-181, 2015.

5 Tolaney SM, Partridge AH, Sheib RG, Burstein HJ and Winer EP: Pneumocystis carinii pneumonia during dose-dense chemotherapy for breast cancer. J Clin Oncol 24: 5330-5331, 2006.

6 Kuik KT, Trubiano J, Worth LJ, Harun NS, Steinfort D and Johnson D: Pneumocystis jirovecii pneumonia following everolimus treatment of metastatic breast cancer. Med Mycol Case Rep 6: 34-36, 2014.

7 Lui A, New J, Ogony J, Thomas S and Lewis-Wambi J: Everolimus downregulates estrogen receptor and induces autophagy in aromatase inhibitor-resistant breast cancer cells. BMC Cancer 16: 487, 2016.

8 Hardinger KL, Koch MJ and Brennan DC: Current and future immunosuppressive strategies in renal transplantation. Pharmacotherapy 24: 1159-1176, 2004.

9 Sulkowska K, Palczewski P, Miszewska-Szyszkowska D, Durlik M, Golebiowski M and Malkowski P: Early everolimus-induced pneumonitis in a renal transplant recipient: A case report. Ann Transplant 17: 144-148, 2012.

10 Suzuki T, Tada Y, Tsushima K, Terada J, Sakurai T, Watanabe A, Kasahara Y, Tanabe N and Tatsumi K: Pneumocystis pneumonia in everolimus therapy: An indistinguishable case from drug induced interstitial lung disease. Respir Med Case Rep 10: 2730, 2013.

11 Carbonnaux M, Molin Y, Souquet PJ, Tantin A, Lombard-Bohas $\mathrm{C}$ and Walter T: Pneumocystis jirovecii pneumonia under everolimus in two patients with metastatic pancreatic neuroendocrine tumors. Invest New Drugs 32: 1308-1310, 2014.

12 Cuzick J, Sestak I, Baum M, Buzdar A, Howell A, Dowsett M, Forbes JF and investigators AL: Effect of anastrozole and tamoxifen as adjuvant treatment for early-stage breast cancer: 10-year analysis of the ATAC trial. Lancet Oncol 11: 1135-1141, 2010.

13 deGraffenried LA, Friedrichs WE, Russell DH, Donzis EJ, Middleton AK, Silva JM, Roth RA and Hidalgo M: Inhibition of mTOR activity restores tamoxifen response in breast cancer cells with aberrant Akt Activity. Clin Cancer Res 10: 8059-8067, 2004.

14 Baroja-Mazo A, Revilla-Nuin B, Ramirez P and Pons JA: Immunosuppressive potency of mechanistic target of rapamycin inhibitors in solid-organ transplantation. World J Transplant 6: 183-192, 2016.

15 Delgoffe GM and Powell JD: mTOR: taking cues from the immune microenvironment. Immunology 127: 459-465, 2009.
16 Delgoffe GM, Kole TP, Zheng Y, Zarek PE, Matthews KL, Xiao B, Worley PF, Kozma SC and Powell JD: The mTOR kinase differentially regulates effector and regulatory $\mathrm{T}$ cell lineage commitment. Immunity 30: 832-844, 2009.

17 Rao RR, Li Q, Odunsi K and Shrikant PA: The mTOR kinase determines effector versus memory $\mathrm{CD}^{+} \mathrm{T}$ cell fate by regulating the expression of transcription factors T-bet and Eomesodermin. Immunity 32: 67-78, 2010.

18 Sinclair LV, Finlay D, Feijoo C, Cornish GH, Gray A, Ager A, Okkenhaug K, Hagenbeek TJ, Spits $\mathrm{H}$ and Cantrell DA: Phosphatidylinositol-3-OH kinase and nutrient-sensing mTOR pathways control T lymphocyte trafficking. Nat Immunol 9: 513$521,2008$.

19 Mansharamani NG, Garland R, Delaney D and Koziel H: Management and outcome patterns for adult Pneumocystis carinii pneumonia, 1985 to 1995: comparison of HIV-associated cases to other immunocompromised states. Chest 118: 704-711, 2000.

20 Sepkowitz KA: Pneumocystis carinii pneumonia among patients with neoplastic disease. Semin Respir Infect 7: 114-121, 1992.

$21 \mathrm{Su}$ YS, Lu JJ, Perng CL and Chang FY: Pneumocystis jirovecii pneumonia in patients with and without human immunodeficiency virus infection. J Microbiol Immunol Infect 41: 478-482, 2008.

22 Roblot F, Godet C, Le Moal G, Garo B, Faouzi Souala M, Dary M, De Gentile L, Gandji JA, Guimard Y, Lacroix C, Roblot P and Becq-Giraudon B: Analysis of underlying diseases and prognosis factors associated with Pneumocystis carinii pneumonia in immunocompromised HIV-negative patients. Eur J Clin Microbiol Infect Dis 21: 523-531, 2002.

23 Li MC, Lee NY, Lee CC, Lee HC, Chang CM and Ko WC: Pneumocystis jiroveci pneumonia in immunocompromised patients: delayed diagnosis and poor outcomes in non-HIVinfected individuals. J Microbiol Immunol Infect 47: 42-47, 2014.

24 Azoulay E, Bergeron A, Chevret S, Bele N, Schlemmer B and Menotti J: Polymerase chain reaction for diagnosing pneumocystis pneumonia in non-HIV immunocompromised patients with pulmonary infiltrates. Chest 135: 655-661, 2009.

25 Kamada T, Furuta K and Tomioka H: Pneumocystis pneumonia associated with human immunodeficiency virus infection without elevated (1 --> 3)-beta-D glucan: A case report. Respir Med Case Rep 18: 73-75, 2016.

26 Fan LC, Lu HW, Cheng KB, Li HP and Xu JF: Evaluation of PCR in bronchoalveolar lavage fluid for diagnosis of Pneumocystis jirovecii pneumonia: a bivariate meta-analysis and systematic review. PLoS One 8: e73099, 2013.

27 Lipschik GY, Gill VJ, Lundgren JD, Andrawis VA, Nelson NA, Nielsen JO, Ognibene FP and Kovacs JA: Improved diagnosis of Pneumocystis carinii infection by polymerase chain reaction on induced sputum and blood. Lancet 340: 203-206, 1992. 